\title{
5
}

\section{The P103 Service Creation Environment Model}

\author{
Carla Capellmann
}

Deutsche Telekom AG, Technologiezentrum Darmstadt

P.O.Box 100003, D-64276 Darmstadt

Tel.: +49 6151 83-3070, Fax: +496151 83-4221,

E-mail: capellmann@fz.telekom.de

\section{Kjell Hermansen}

Telenor Research and Development

Instituttveien 23, Postboks 83, N 2007 Kjeller, Norway

Tel: +47 638091 00, Fax: +4763810076

E-mail: Kjell.Hermansen@kjeller.fou.telenor.no

Parminder Mudhar

BT Laboratories, Martlesham Heath, Ipswich IP5 7RE, UK

Tel +44473 642849, fax +44 473637400

E-mail: parminder.mudhar@bt-sys.bt.co.uk

Jørgen Nørgaard

Tele Danmark Research

Lyngsø Allé 2, DK-2970 Hørsholm, Denmark

Tel: +45 4576 6444, Fax: +45 4576 6336,

E-mail:jnp@tdr.dk, URL: http://www.tdr.dk/ jnp

\begin{abstract}
One of the major objectives of the Intelligent Network concept is the rapid introduction of new services and features. The development of new services, from initial idea to implementation, called service creation, is therefore a vital process in the achievement of this objective. Within EURESCOM project P103 "Evolution of the Intelligent Network", the activity to support service creation, i.e. the service creation environment, was closely investigated. A ge-
\end{abstract}


neric model for the process of service creation was developed that covers a broad range of different service creation scenarios. This paper presents the P103 service creation environment model, thereby introducing important concepts of service creation and related aspects.

\section{INTRODUCTION}

The Intelligent Network (IN) is an architectural concept for the rapid introduction of new services and features into the network. For this, the process of developing new services, called service creation, is vital in order to reduce development costs and time-to-market of new services. It was one of the major objectives of EURESCOM ${ }^{1}$ project P103 "Evolution of the Intelligent Network" [Vaar94] to investigate closely the complex task of service creation. A generic model, the so-called P103 service creation environment (SCE) model, was developed that describes the different service creation activities. Figure 1 illustrates the problem domain.

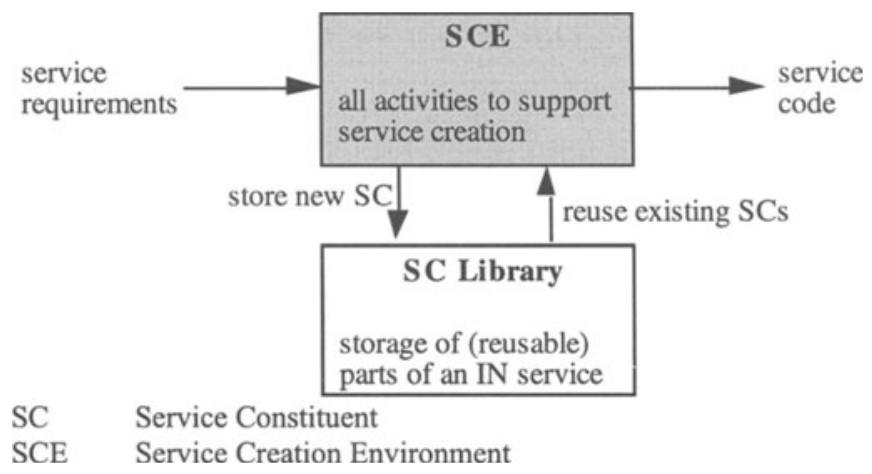

Figure 1 Problem domain.

Service creation is the transformation of often vague and imprecise requirements for a new service into code that implements the required service. To enable rapid and efficient service creation, the process is based on reuse. Existing service components, called service constituents in P103, are reused during the creation of a new service, whenever possible. Service creation environment is here defined as the encapsulation of all activities required to support service creation. The P103 SCE model specifies such an environment, i.e. it models the process of service creation.

In the following section the prerequisites for modelling the service creation environment, the P103 service life cycle and the P103 modelling technique, are introduced. Next the model and some of its major components will be presented. Finally, a summary will be given and the achieved results will be discussed.

\footnotetext{
${ }^{1}$ EURESCOM is a consortium formed by a wide number of European network operators in order to initiate, coordinate and supervise research and strategic studies in the field of telecommunications.
} 
The aim of this paper, besides of course introducing the P103 SCE model, is to give a general overview on service creation and to highlight some important aspects in this area. The paper will not present any concrete or existing SCE tool though the model may serve as reference or basis for developing, assessing and/or comparing SCE tools.

\section{PREREQUISITES}

\subsection{The P103 service life cycle}

Starting point for the development of the P103 SCE model was the P103 service life cycle [P103TR3]. A service life cycle describes all the phases a service may be subject to through its entire life. Each phase defines the actions that can be prescribed to the service in that phase. Phases may be divided into sub phases called activities. The P103 service life cycle defines three phases: service creation, service deployment (including service withdrawal) and service utilisation. Figure 2 shows part of this life cycle, the service creation phase, which consists of six activities: requirements capture, analysis, specification, design, implementation and testing.

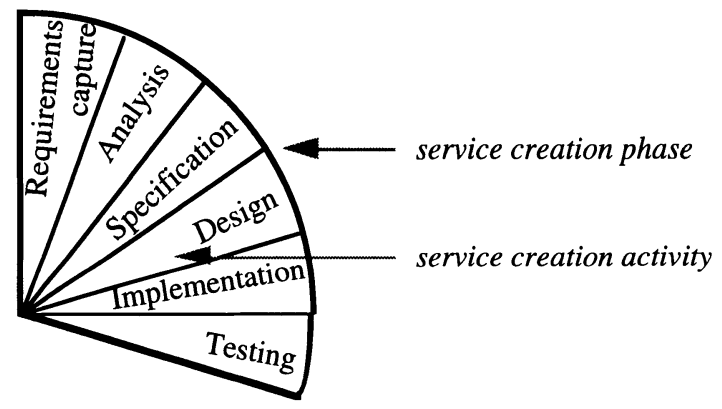

Figure 2 Service creation phase of $\mathrm{P} 103$ service life cycle.

In order to provide a structured description for each phase and activity, P103 developed a scheme for the description of the service life cycle activities. Each activity is defined in terms of its purpose, the required inputs and generated outputs, the tasks or actions to be carried out, the participants related to or involved and eventual requirements to the environment. Figure 3 gives an example of such an activity description.

\subsection{The P103 modelling technique}

The goal of the P103 service creation work was to describe the service creation process. The approach taken is based on the usage of an object-oriented method developed within the project, the P103 service composition technique [P103TR2]. This technique is based on OOram 
(object-oriented role analysis and modelling, [Reen92]), MSCs (message sequence charts, [Z.120]) and SDL-92 (not used in the SCE model, [Z.100]). Although the method was developed to model services, it is perfectly suited to describe processes. Role modelling which plays a central part in the method, is especially suitable to describe tasks or responsibilities to be taken during the different service creation activities, and MSCs provide a good means to visualise dynamic aspects within the service creation environment.

\begin{tabular}{|ll|}
\hline Acticity & \multicolumn{1}{c|}{ Service Specification } \\
\hline Purpose & To derive a formal description of the service behaviour \\
\cline { 2 - 2 } Input & Service requirements \\
Output & Service specification \\
Actions & $\begin{array}{l}\text { To specify the service using a formal description technique } \\
\text { To validate the service specification }\end{array}$ \\
& .. \\
Actors & $\begin{array}{l}\text { Service creator } \\
\text { Requirements to environment } \\
\text { Access to service requirements } \\
\text { Access to existing specifications } \\
\text {... }\end{array}$ \\
\hline
\end{tabular}

Figure 3 Example for an activity description.

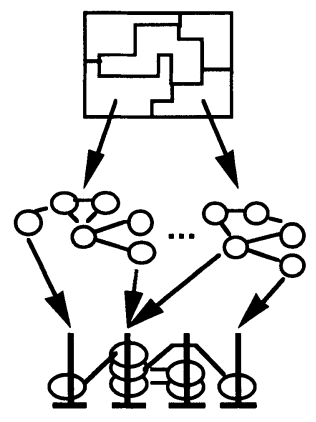

Divide into areas of concern

Elaborate separate role models

Synthesise role models

Figure 4 Main steps of the P103 modelling technique.

The main steps of the method are illustrated in Figure 4. First, the problem domain, here the service creation phase, is divided into different areas of concern, each of which can be treated independently of the others. Note that this step can be applied iteratively. The service creation phase is divided into its different activities, each of which again may be broken down into 
smaller tasks or areas of concern. For these areas of concern, so-called role models will be developed in the second step. A role model describes a problem domain in terms of roles and their collaboration structure. Thereby, a role defines the responsibilities of an object in the structure of collaborating roles. According to the method, the role behaviour is specified using SDL-92. This has not been done for the SCE model though; here the roles are described in prose. The messages that the roles can exchange are defined by contracts. Typical message exchanges may be described in form of MSCs. In a last step, the different role models are synthesised together by merging problem inherently related roles. Synthesis may also be applied iteratively.

\section{THE MODEL AND ITS COMPONENTS}

\subsection{The SCE model}

The P103 SCE model describes the service creation activities identified in the P103 service life cycle in terms of roles and relationships between them. Depending on the complexity of the activity at hand, several models describing its different aspects may exist. By merging roles the individual role models are synthesised in order to describe the complete activity and then the service creation process. Altogether the P103 SCE model contains 17 role models and 42 unique roles. An overview of this model is given in Figure 6, the complete model will not be included here. Besides the role diagram that graphically presents roles and their relationships, the model description contains textual descriptions of the area of concern, stimuli to and responses from the model ${ }^{2}$, its roles and contracts (see Figure 5). In addition, many MSCs exist that describe typical interaction scenarios. An example for one such scenario is given in Figure 7. For a detailed description of the model, see [P103TR3].

The service creation process will be stimulated by a service creation Client, a role that requests a service to be created (see Figures 5 and 6). The request will be received and handled by the Service Creation Coordinator (see Figure 6). This role ensures that the Client has a single point of contact for meeting its service creation requests, and it takes care of the coordination of the creation process.

Although the main purpose of the service creation process is the creation of a service, it may also be possible for a Client to ask only for "intermediate" results, e.g. service requirements, specification, etc. The model thus covers the complete service creation process as well as the individual activities and any (reasonable) combination thereof.

In the course of its creation, the service will go through different activities within the service creation phase. Normally, the creation process will start with collecting the requirements for the new service (activity requirements capture). The collected requirements will be analysed with respect to consistency, completeness, service interaction, and realisation (activity requirements analysis). On this basis a consistent formal specification of the service will be derived (activity service specification). Note that the specification activity includes the vali-

\footnotetext{
2 Stimulus/response pairs are part of a complete description of a role model. A stimulus is a message spontaneously created by one role of the model. It triggers certain events within the model and leads to a corresponding response.
} 


\begin{tabular}{|c|c|c|c|}
\hline \multicolumn{4}{|c|}{ Service Creation Environment } \\
\hline \multicolumn{4}{|c|}{ Area of concern } \\
\hline \multicolumn{4}{|c|}{ The creation of a service } \\
\hline \multicolumn{3}{|l|}{ Stimulus } & Response \\
\hline \multicolumn{3}{|c|}{ create a service } & created service \\
\hline \multicolumn{3}{|l|}{$\cdots$} & $\cdots$ \\
\hline \multicolumn{4}{|l|}{ Roles } \\
\hline Client & \multicolumn{3}{|c|}{ Role that requests a new service } \\
\hline$\cdots$ & \multicolumn{2}{|c|}{$\cdots$} & \\
\hline \multicolumn{4}{|c|}{ Contracts } \\
\hline Contract & From & To & Message \\
\hline cs & Client & $\begin{array}{l}\text { Service } \\
\text { Creation Co- } \\
\text { ordinator }\end{array}$ & $\begin{array}{l}\text { createService (ServiceID) } \\
\text { createSpec (ServiceID) } \\
\text {... }\end{array}$ \\
\hline$\ldots$ & $\ldots$ & $\ldots$ & $\ldots$ \\
\hline
\end{tabular}

Figure 5 Part of the SCE model description.

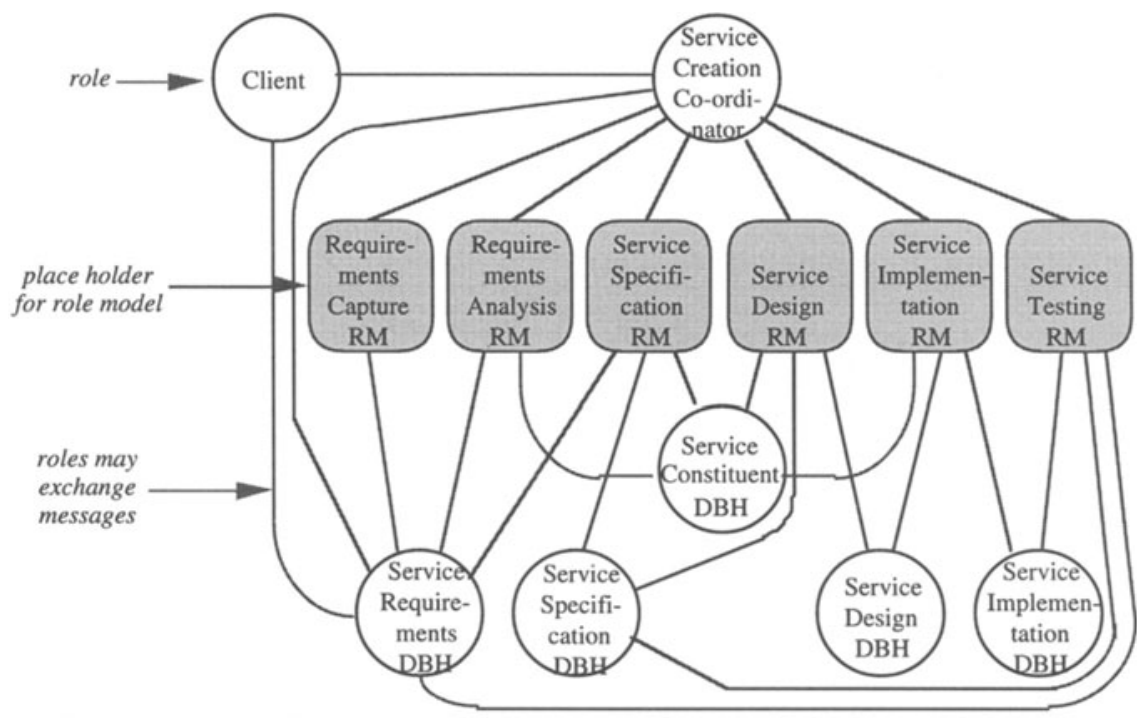

DBH Data Base Handler

RM Role Model

Figure 6 Overview of the P103 SCE model. 
dation of the specification. From the specification the service structure to be implemented will be derived (activity service design), and code for distribution in the network will be generated (activity service implementation). Again it has to be mentioned that also these activities cover a validation of the results obtained. In the last activity of service creation, it will be checked that the service implementation fulfills its requirements and specification (activity service testing). Although this "normal" path through the service creation process is likely to occur often, it is not a must. Jump-backs to earlier activities are possible as well as forward-jumps to later activities in special cases where an activity might be omitted. The coordination of the sequence of the activities lies in the responsibility of the Service Creation Coordinator, who takes care of initiating activities, receiving the results and asking the Client for information or decisions, if necessary (see Figure 7 for a simple interaction scenario).

Each service creation activity is described in detail by separate role models, not included here. The overview diagram in Figure 6 only indicates these models (see rounded boxes in the figure).

During service creation a lot of information about the service (and its components) is created and used. This information is maintained by the different data base handler (DBH) roles at the bottom of the diagram in Figure 6. By providing the information needed in different creation activities, the DBH roles glue the service creation activities together. In the overview diagram in Figure 6, four DBH roles are assumed to store service related information whereas there is only one DBH role defined to store and maintain service constituents. It is as well possible to define just one DBH role for services or one DBH role to store both, services and service constituents. A fine grained structure with several data base handlers shows explicitly which information an activity requires, e.g. the identified service requirements are needed as input in the analysis, specification and testing activity whereas the service design is only input to the implementation activity. Which model is the most adequate can not be said in general. This depends on the model's purpose. The data base handlers are also essential to enable a reuse-based service creation process. Further aspects of storage of information in a service creation environment will be discussed in section 3.2.

The SCE role model may be characterised as follows. It

- is consistent with the service creation phase of the P103 service life cycle.

- does not put unnecessary constraints on the sequence in which the service creation phases may be run through.

- provides a general framework for service creation which does not impose unnecessary constraints on the service creation process, since the SCE model covers all individual models of the service creation activities without restricting the way they may be combined.

- reflects the reuse-driven approach towards service creation. The role models for the different activities are designed in such a way that reuse of existing results is integrated in the model whenever this makes sense. 


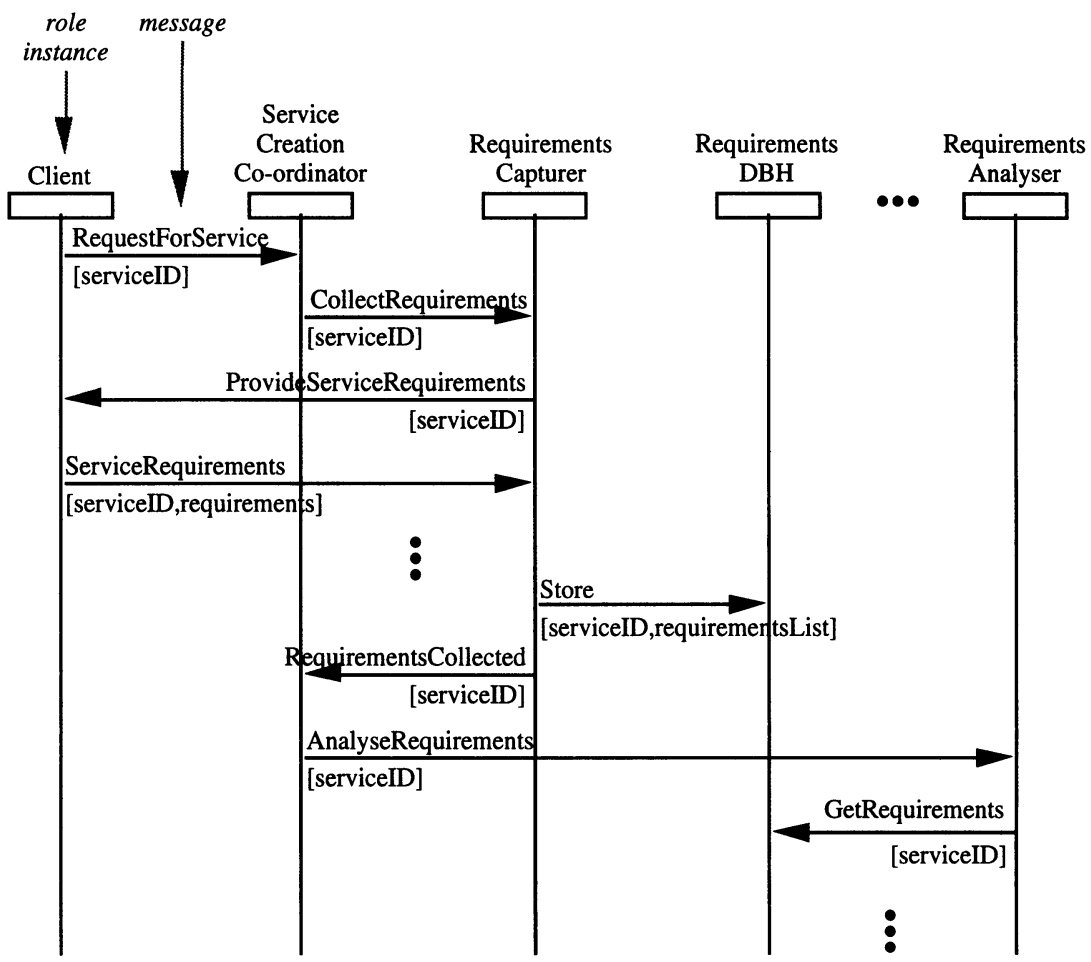

Figure 7 Example of an interaction scenario, represented as MSC.

The model presented so far captures the tasks to be performed during service creation in form of roles, and their relationships in form of contracts and interaction scenarios. Other important aspects like

- what information is important during service creation and how it may/should be organised (in order to support reuse),

- how to perform complex tasks like service specification and design, service interaction handling or reuse,

were also looked at. They are briefly discussed in the next two sections.

\subsection{Reference model for storage}

During service creation, a lot of information is generated and needed as input for different tasks or activities. Storage and maintenance of all this information so that it is available where it is required, and search and retrieval of certain information are essential for efficient and effective service creation. They become even more important in a reuse based creation proc- 
ess where a lot of information has to be maintained and very good search and retrieval facilities are needed. The problem of what information has to be stored and how to support search and retrieval is thus crucial for the definition of a service creation environment model. In P103 such a storage component (see SC Library in Figure 1) was therefore investigated more closely. A model describing what information should be maintained and in which structure was developed, always keeping reuse aspects in mind. The model is based on work carried out in the RACE project SCORE [SCORE93]. Figure 8 presents an overview of this model, the P103 component model. It is given in OMT notation [Rumb91].

The elements to be stored during service creation, here called components, may either be services or service constituents (reusable parts of IN services). For each component, three types of information are maintained:

- Administrative information: Here all the general information about a component is kept that is needed to administer an eventually big set of components. Examples of such information are the unique component identifier, the component owner or the (development) history, to mention only a few.

- Network related information: Here the information concerning network specific aspects of the component is stored, e.g. network requirements or target architecture.

- Role model: This is the core part of each component where its essence is described. Since in P103 services as well as service constituents are represented as role models, this core information about the component is structured according to the information kept in a role model, like area of concern, stimulus/response pairs, role diagram and so on. In addition, other information important during service creation like information required for service interaction handling (properties), information relevant for testing (test cases), or information about relationships between components (uses/used-in links) are stored here.

Note that the diagram in Figure 8 gives only the high-level information structure of a component. Some of the attributes are themselves defined as complex structures.

The component model defines the information structure of services and service constituents as required during the service creation process. It may thus be seen as one possible candidate for realising a data base handler within a service creation environment (see data base handler roles in Figure 6). In order to support reuse of components, search and retrieval functions play a very important role. The problem of efficient search and retrieval is a complex and difficult subject. Although the problem is not new, no general solution has been found yet. Within P103 a list of requirements was compiled that describe aspects relevant for efficient search and retrieval.

\subsection{Important aspects: reuse and service interaction}

Several sets of guidelines enhance the SCE model with respect to the support of reuse, service analysis, specification and design, service interaction handling and the incorporation of security aspects. In the following, reuse and guidelines supporting a reuse based service creation process as well as service interaction and how to handle this problem during service creation will be discussed. 


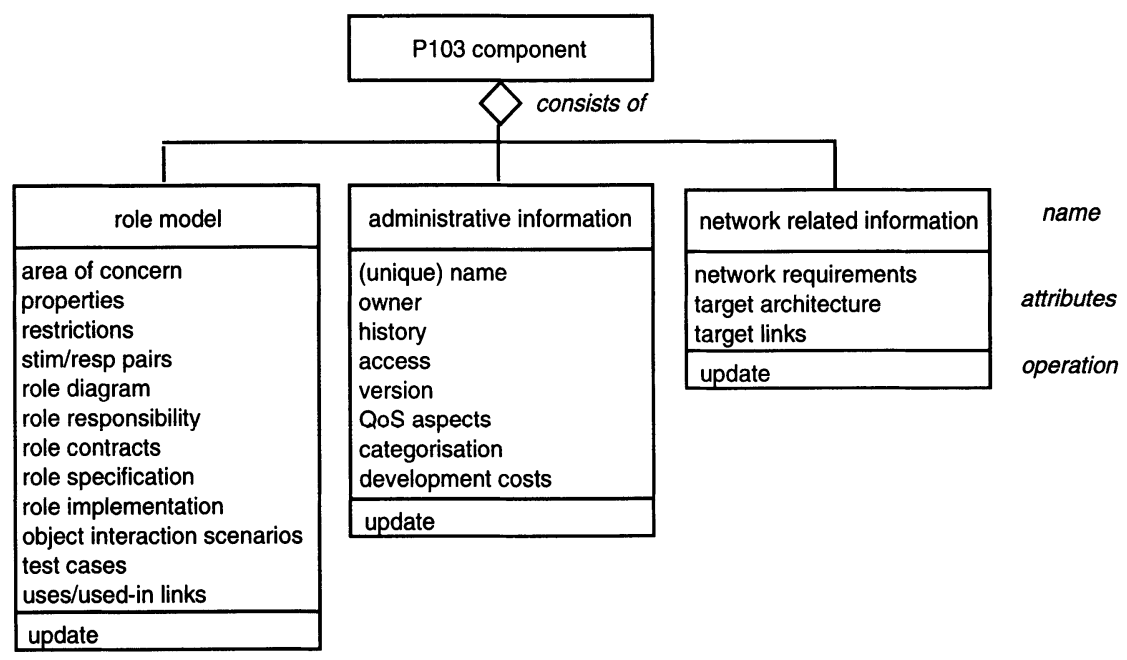

Figure 8 P103 component model.

\subsubsection{Reuse}

Reuse is one of the most popular buzzwords these days. Its appeal lies in the promise for (more) efficient software/service development. New developments can build on already existing components, thus saving development time and costs as well as reducing testing effort. Thus it is quite obvious that reuse of existing service components during the creation of new services is crucial for rapid service creation. Despite all these promises, one has to be aware that reuse is still an open issue in object-oriented research. Within P103, one step towards its concretisation was undertaken by developing guidelines to support reuse during service creation. These guidelines describe for each service creation activity what may be reused in this activity and in which way.

In general, the level of reusability (during service creation) is determined by several factors. In order to reuse a service component in different services, it needs to be independent of a specific service ${ }^{3}$. Reuse also depends on the way components are stored: information structure, search and retrieval strategies, etc. (see section 3.2). Another factor that influences the level of reusability, is the quality of the already existing components, their size and structure, with a trade-off between the latter two.

\subsubsection{Service interaction}

Service interaction is seen as one of the major obstacles to rapid service creation. The problem may arise that the operation of new services/features (unexpectedly) influences and alters the behaviour of the existing services. Figure 9 shows a well-known example where IN services CFU (Call Forwarding Unconditional) and SCR (Selective Call Rejection) interact.

\footnotetext{
${ }^{3}$ For a more general discussion of the notion of service independence, see [MuLiMi94].
} 


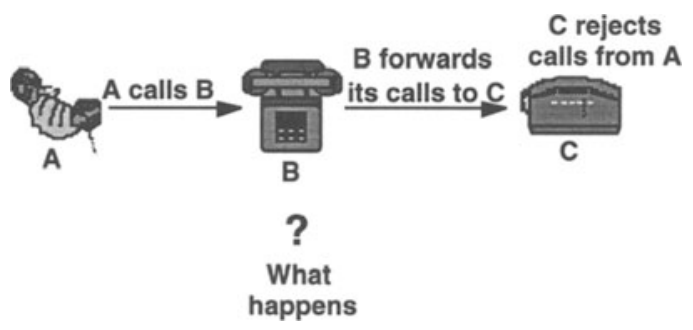

Figure 9 Example to illustrate the problem of service interaction.

In general there exist different ways how to handle the service interaction problem:

- Avoidance: Services (and networks) are developed in such a way that no interactions occur. However, this is quite unrealistic.

- Detection: (During service creation) potential service interactions are identified.

- Resolution: A solution to known interactions is provided.

Note that the problem of service interaction needs to be addressed during the complete service life cycle. Some interactions can be detected during service creation, whereas others will only be found out during service execution. Some interactions can be resolved reasonably during service creation, whereas others are better handled during service execution.

P103 has addressed service interaction during service creation only. Places in the P103 SCE model have been identified where service interaction should be handled. In addition to this, guidelines have been developed how to detect and resolve interactions. These guidelines were specifically developed in relationship with the P103 modelling technique. They are defined based on the concept of service properties.

\section{SUMMARY AND CONCLUSIONS}

A generic model of a service creation environment for future intelligent networks, as developed within EURESCOM project P103, "Evolution of the Intelligent Network", has been presented. Aim of the SCE model is to provide an universal framework for service creation. The model covers different aspects related to the service creation phase of the service life cycle. It integrates service interaction and security ${ }^{4}$ issues in the process of service creation and incorporates a model for component storage. The P103 SCE model was elaborated using an object-oriented modelling technique developed within the project.

The SCE model is enhanced by several sets of guidelines that were not included here. Reuse guidelines state for each service creation activity what may be reused in this activity and which aspects have to be considered during reuse. Guidelines for handling service interaction in the different activities are defined based on the concept of service properties and in relationship with the P103 service modelling technique. Concepts and guidelines how to incorpo-

\footnotetext{
${ }^{4}$ Not covered in this paper; for more information, see [P103TR3].
} 
rate security aspects into a new service right from the start are defined as well. In order to support the analysis, specification and design activities, the P103 modelling technique may be used.

By presenting parts of the P103 SCE work, important aspects of service creation like

- the different service creation activities,

- reuse of existing service components,

- storage of information,

- handling of service interaction

have been discussed. Others, like the integration of security issues or a smooth transition to service deployment/management, could not be included here.

In its overview diagram (see Figure 6), the P103 SCE model clearly indicates the major parts of service creation environments:

- functions that support the creation process (encapsulated in the Service Creation Coordinator,

- functions that maintain the creation data (data base handler roles), and

- tools that are used during the creation activities and work on the creation data (role models for creation activities).

In that sense, the P103 model is in line with the ECMA reference model for CASE environment frameworks (see [ECMA]), although both models were developed completely independent of each other.

The P103 SCE model may serve as a basis for

- the comparison of existing SCE tools,

- a requirements list to SCE tool developers,

- the specification of a company specific service creation environment (for a discussion and illustration of the derivation of a specific SCE, see [Cap95]),

- the development of a SCE reference model.

\section{ACKNOWLEDGMENT}

The P103 Service Creation Environment Model was elaborated in the EURESCOM project P103 "Evolution of the Intelligent Network". Thanks are thus due to all partners who participated in the project, especially to those people who contributed to the development of the SCE model, namely Pierre Combes (France Telecom), Raymond Nilsen (Norwegian Telecom Research), Tapio Vaarnamo (Telecom Finland), Raúl Guitérrez and Marisa Felipe (both Telefónica de España).

\section{ABBREVIATIONS}

CFU Call Forwarding Unconditional

DBH Data Base Handler 
MSC Message Sequence Chart

OMT Object Modelling Technique

OOram Object Oriented Role Analysis and Modelling

RM Role Model

SC Service Constituent

SCE Service Creation Environment

SCR Selective Call Rejection

SDL Specification and Description Language

\section{REFERENCES}

[Cap95] Capellmann, C.: A Generic Service Creation Environment. In Proceedings of TINA'95, Melbourne/Australia, February 1995.

[ECMA] Earl, A.: A Reference Model for Computer Assisted Software Engineering Environment Frameworks. In: Softwaretechnik-Trends, Band 11 Heft 2, Mai 1991. (also published as ECMA Technical Report TR/55).

[P103TR2] EURESCOM Project P103: Guidelines for Service Creation and Composition. Technical Report No 2, December 1994.

[P103TR3] EURESCOM Project P103: Service Creation Environment. Technical Report No 3, December 1994.

[Reen92] Reenskaug, T. et.al.: OORASS: Seamless support for the creation and maintenance of object oriented systems. Journal of Object-Oriented Programming, October 1992.

[Rumb91] Rumbaugh et.al.: Object-Oriented Modelling and Design. Prentice-Hall, 1991.

[SCORE93] The SCORE Component Model. Deliverable D104 Volume II, 1993.

[Vaar94] Vaarnamo, T. (ed). EURESCOM project P103, Deliverable No 6a. 12/1994.

[Z.100] ITU (CCITT) Recommendation Z.100, "SDL", 1992, Revised Recommendation.

[Z.120] ITU (CCITT) Recommendation Z.120, "Message Sequence Charts", 1992. 


\section{BIOGRAPHY}

Carla Capellmann studied Computer Science at the University of Koblenz. After having finished her studies in 1991, she joined Deutsche Telekom AG, Technologiezentrum at Darmstadt. She is member of the research group "Functional Aspects of Networks" which deals with Intelligent Networks, Telecommunication Management Networks, and Formal Description Techniques. In EURESCOM project P103 "Evolution of the Intelligent Network", she worked on service creation and methodology aspects. Currently she is task leader within EURESCOM project P509 "Handling Service Interaction in the Service Life Cycle". She is also involved in EURESCOM project P508 "Evolution, Migration Paths and Interworking with TINA".

Mr. K. Hermansen holds a Ph.D. in physics from the University of Oslo. He has been involved in narrowband data and broadband projects at Telenor R\&D. Currently he is working on services in Intelligent Networks.

Jørgen Nørgaard graduated with a MSc. in computer science from the Computer Science department at Aarhus University, Denmark. After joining Tele Danmark Research, he has been working at the software engineering department and participated in the RACE Cassiopeia project and in the EURESCOM P103 project in which he lead the task on activities for service creation and methodology work. At the computer science department at Aarhus University he co-designed and developed an open, distributed hypermedia system on object oriented database system and the $\mathrm{X}$ window system. At Nokia Telecommunications he worked with object oriented techniques and their application in telecommunications software, using the notation SDL-92 and OMT. 